\title{
Os filmes e jogos didáticos no trabalho educativo com reeducação alimentar
}

\section{The films and didactic games in the educational work with alimentary reeducation}

Daniele Bremm (bremmdaniele@gmail.com)

Universidade Federal da Fronteira Sul- UFFS

Resumo: Este trabalho dialoga sobre o uso de filmes e de jogos como ferramentas didáticas para trabalhar conceitos de Ciências, a partir do desenvolvimento de um conjunto de aulas produzidas em uma escola pública do município de Cerro Largo- RS, por meio da intervenção do Programa de Educação Tutorial - PETCiências da Universidade Federal da Fronteira Sul (UFFS). Para o conteúdo de educação alimentar, utilizou-se o filme: "Muito além do peso", com o objetivo de sensibilizar os alunos em relação aos seus hábitos alimentares. Na sequência utilizou-se de um jogo didático com degustação de alimentos para resolver a problemática da associação da vitamina as suas respectivas fontes. O objetivo deste trabalho é realizar uma análise das potencialidades dos filmes e jogos didáticos para trabalhar a educação alimentar. Podemos perceber que o uso de filmes como ferramenta didática facilita a sensibilização dos alunos, uma vez que o audiovisual é algo que chama muito a atenção dos pequenos, podendo assim, ser usado com facilidade para iniciar a educação alimentar. A aprendizagem de experiências através dos sentidos, realizada através do jogo também se mostrou efetiva para a aprendizagem resolvendo o problema que a turma apresentava para relacionar a vitamina e as suas fontes.

Palavras-chave: Educação em ciências; Formação de professores; Metodologias de ensino.

Abstract: This paper discusses the use of films and games as didactic tools to work on science concepts, based on the development of a set of classes produced in a public school in Cerro Largo-RS, through the intervention of the Education Program. Tutorial - PETCiencias of the Universidade Federal da Fronteira Sul (UFFS). For the content of food education, the film "Far beyond weight" was used to sensitize students about their eating habits. Then, a didactic game with food tasting was used to solve the problem of the association of the vitamin with its respective sources. The aim of this paper is to perform an analysis of the potential of films and didactic games to work on food education. We can see that the use of films as a didactic tool facilitates the students' sensitization, since the audiovisual is something that catches the attention of 


\section{Vol. 2, n. 3 - Edição Especial: Ciclos Formativos em Ensino de Ciências.}

the little ones, so it can be easily used to start the food education. The learning of experiences through the senses, performed through the game also proved effective for learning by solving the problem that the class presented to relate the vitamin and its sources.

Keywords: Science education; Teacher training; Teaching methodologies.

\section{INTRODUÇÃO}

Em um mundo em que as novidades e os avanços em relação à informação estão por toda a parte, o ensino precisa ser realizado de uma forma que venha a estimular os alunos. Uma vez que a escola também se alterou e se mostra cada vez mais como um espaço de diversidade, precisamos adaptar as nossas práticas e metodologias de ensino de forma a atender a todos os sujeitos, pois cada aluno aprende de uma forma diferente.

Metodologias diferenciadas vem sendo utilizadas para tornar o ensino mais dinâmico, estas podem levar em consideração as Tecnologias da Informação (TI), motivando assim, o aluno para a aprendizagem. Metodologias diferenciadas podem também levar em conta a utilização de jogos didáticos e filmes, pois através deles o aluno aprende a questionar, a relacionar, a construir argumentos e conceitos, (ALVES; BIANCHIN, 2010). Além disso, os filmes e jogos didáticos possibilitam diálogo e sistematização durante o seu desenvolvimento, uma vez que permitem a inserção de perguntas mediadoras pelo professor, o que favorece muito a aprendizagem e a significação das concepções/conceitos dos alunos.

Este relato de experiências tem como tema central um conjunto de aulas, onde se buscou através do uso de filmes e de jogos didáticos, trabalhar conceitos de Ciências voltados para a educação alimentar. O filme foi utilizado como uma forma de abordar o conteúdo de educação alimentar e também como estratégia de sensibilizar os alunos para a sua realidade alimentar. A utilização do jogo didático partiu da necessidade percebida pela professora e pela bolsista do PETCiências, do Programa de Educação Tutorial - PET (MEC/FNDE /SESu) ambos desenvolvidos na Universidade Federal da Fronteira Sul (UFFS) no Campus Cerro Largo, em realizar uma atividade que ajudasse os alunos a relacionarem as vitaminas com as suas respectivas fontes. As atividades 


\section{Vol. 2, n. 3 - Edição Especial: Ciclos Formativos em Ensino de Ciências.}

foram realizadas junto a uma turma do oitavo ano de uma escola pública do município de Cerro Largo - RS.

Através da aplicação deste bloco de aulas objetivamos analisar a potencialidade dos filmes e jogos didáticos na educação alimentar e verificar se a exploração dos sentidos pode interferir de forma positiva na associação de conceitos.

\section{METODOLOGIA}

O presente trabalho se desenvolveu em um bloco de cinco aulas. A primeira aula consistiu na introdução sobre o conteúdo de educação alimentar e foi feita através do filme: "Muito além do peso", com o objetivo de alertar os alunos para o perigo da realidade alimentar atual, principalmente o risco do consumo excessivo de fast food ${ }^{1}$. Durante o vídeo vários alimentos presentes no cotidiano dos alunos foram apresentados juntamente com a quantidade de açúcar e de gordura presente nos mesmos, gerando anotações dos alunos.

A segunda aula consistiu na construção de cartazes, feitos a partir das informações do filme. Para tanto foi solicitado aos alunos que trouxessem embalagens de alimentos com sua informação nutricional, podendo ser os que apareciam no filme. Durante a aula realizamos a análise das embalagens e posteriormente fizemos a pesagem da dosagem de açúcar e de gordura, que era mencionada na embalagem. O açúcar foi colocado em saquinhos que eram anexados aos cartazes juntamente com a embalagem e frase construída pelos alunos ou retirada do filme.

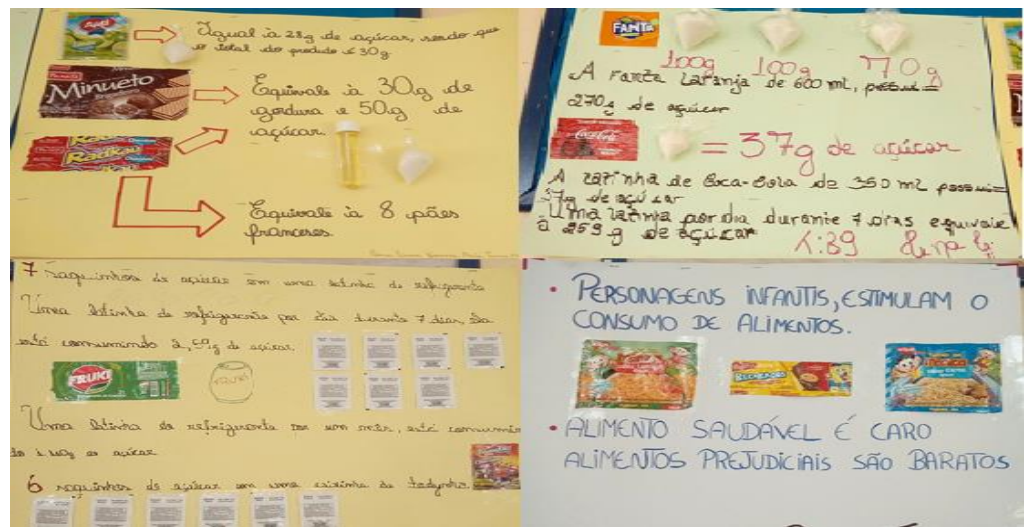

\footnotetext{
${ }^{1}$ Tipo de alimento preparado e servido com rapidez, geralmente envolvendo muita gordura no seu preparo, pode-se considerar como um lanche.
} 


\section{Vol. 2, n. 3 - Edição Especial: Ciclos Formativos em Ensino de Ciências.}

Figura 1- Cartazes confeccionados pelos alunos.

Em uma terceira aula demos início ao conteúdo de vitaminas, durante a atividade percebemos que os alunos apresentaram dificuldades para associá-las aos alimentos que as continham. Objetivando resolver esta questão, desenvolveu-se um quis sobre as vitaminas, com degustação de alimentos. O mesmo consistiu de perguntas de múltipla escolha, que explanavam a função das vitaminas e sua relação com os alimentos. Para tal, as perguntas foram projetadas no Datashow e os alunos foram divididos em grupos, cada grupo recebeu uma sequência de plaquinhas com as alternativas de $\mathrm{A}$ à $\mathrm{D}$, as quais deveriam ser erguidas como forma de expressar a sua resposta. As equipes que não acertavam as questões voltadas para a fonte de cada vitamina deveriam degustar tal alimento, para assim, associar a vitamina ao alimento degustado. Todos os alimentos foram levados pela bolsista e professora sendo de procedência orgânica. As questões elaboradas e alternativas corretas estão dispostas no quadro a seguir: degustados.

Quadro 1 - Perguntas feitas ao longo do jogo, suas respostas indicando os alimentos que foram

\begin{tabular}{|l|l|}
\hline Pergunta & Alternativa correta \\
\hline $\begin{array}{l}\text { 1-Importante no crescimento, pois forma ossos e } \\
\text { dentes, melhora a pele e o cabelo protege o } \\
\text { aparelho respiratório, digestivo e urinário e } \\
\text { também é importante para a visão. A questão se } \\
\text { refere à vitamina? }\end{array}$ & \\
\hline $\begin{array}{l}\text { 2- Onde encontramos vitamina A? } \\
\text { 3- Esta vitamina é fundamental no fortalecimento } \\
\text { dos ossos e dentes e ajuda na coagulação do } \\
\text { sangue. Sintetizada pelo próprio organismo, mas } \\
\text { que depende do sol para se tornar vitamina? }\end{array}$ & Vitamina D \\
\hline $\begin{array}{l}\text { 4- Para que haja melhor aproveitamento do ferro, é } \\
\text { necessário ingeri-lo com alimentos ricos em } \\
\text { vitamina: }\end{array}$ & Vitamina C \\
\hline $\begin{array}{l}\text { 5- Onde encontramos a vitamina C? 7- } \\
\text { 6- Atua no processo de coagulação sanguínea. A } \\
\text { deficiência desta vitamina causa sangramento? }\end{array}$ & Vitamina K \\
\hline 7- Onde encontramos a vitamina K? & Alface \\
\hline
\end{tabular}




\section{Vol. 2, n. 3 - Edição Especial: Ciclos Formativos em Ensino de Ciências.}

\begin{tabular}{|l|l|l|}
\hline $\begin{array}{l}\text { 8- Participa da produção e manutenção do } \\
\text { colágeno, aumenta a absorção de ferro, protege os } \\
\text { constituintes do sangue contra a oxidação, acentua }\end{array}$ & Vitamina C \\
$\begin{array}{l}\text { a resposta imunológica e ajuda na cicatrização? } \\
11 \text { - Entre os alimentos listados a seguir, as } \\
\text { principais fontes de vitamina E são? R: Óleos } \\
\text { vegetais e amêndoas; }\end{array}$ & \\
\hline $\begin{array}{l}\text { 9- Complete: Os ossos são os principais afetados } \\
\text { pela deficiência de vitamina _ causando } \\
\text { raquitismo, tanto em crianças como em adultos? }\end{array}$ & Vitamina D \\
\hline $\begin{array}{l}\text { 10- Onde podemos encontrar vitamina D? } \\
\text { 11- Entre os alimentos listados a seguir, as } \\
\text { principais fontes de vitamina E são? }\end{array}$ & Óleos vegetais e amêndoas \\
\hline
\end{tabular}

A aplicação do jogo aconteceu na quarta aula e em seguida, no segundo período, explanou-se a importância do consumo de alimentos saudáveis, com conhecimento da sua procedência, salientando sobre os orgânicos, alimentos em que as vitaminas são melhor assimiladas pelo nosso organismo. Trabalhou-se a importância da produção orgânica para o meio ambiente por meio de discussão e problematização de temas controversos que apareciam nas charges sobre o assunto. Para finalizar os alunos elaboraram as suas próprias charges.

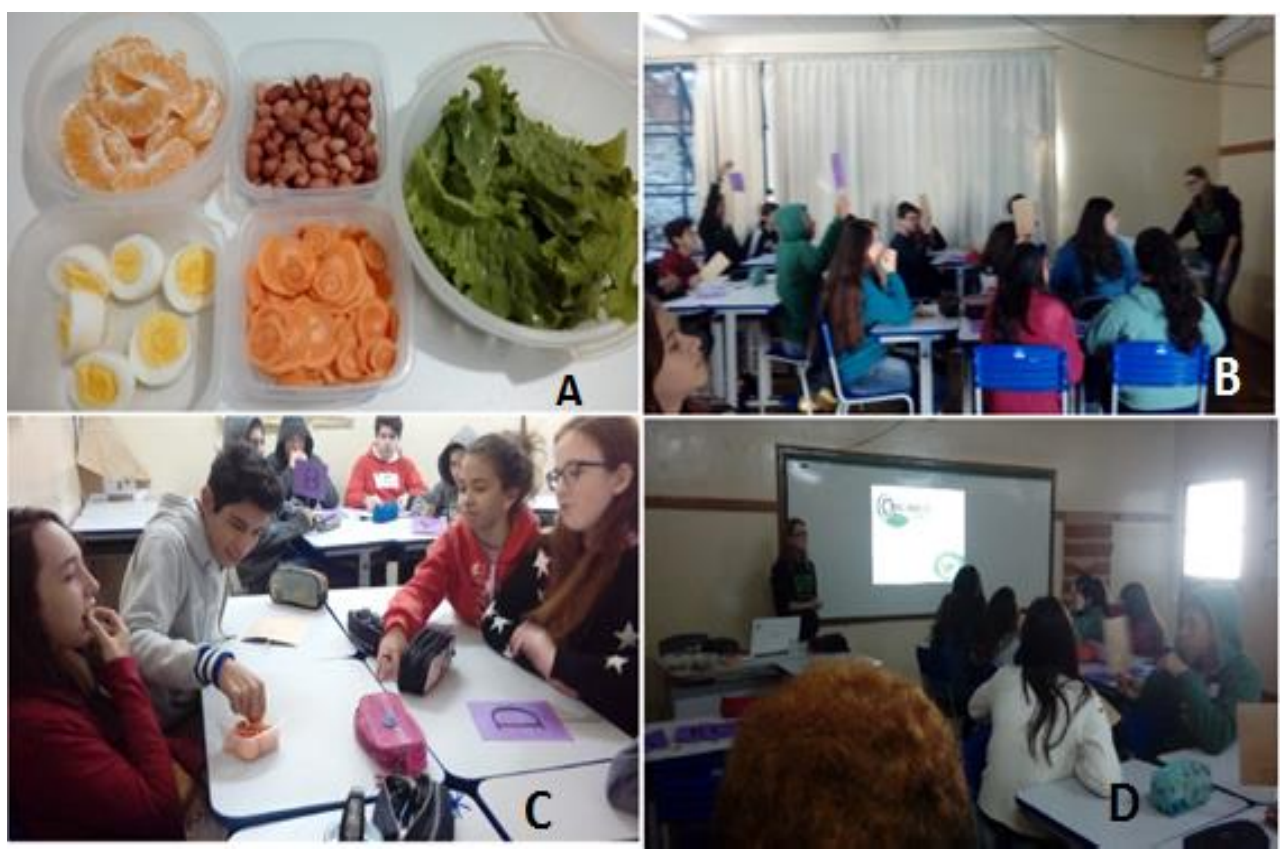




\section{Vol. 2, n. 3 - Edição Especial: Ciclos Formativos em Ensino de Ciências.}

Figura 2 - A- alguns dos alimentos degustados; B- alunos levantando as plaquinhas para sinalizar suas respostas; C- alunos fazendo degustação de um alimento após errarem a reposta; D- quinta aula, ministração sobre alimentos orgânicos.

\section{RESULTADOS}

Resolvemos utilizar os filmes para iniciar o tema da educação alimentar, pois eles são ótimos aliados para a sensibilização dos alunos, assim, conseguimos mais facilmente tratar dos problemas voltados para a alimentação de hoje em dia. Pois, os filmes apresentam:

[...] o adequado equilíbrio entre as palavras e as imagens, facilita os processos de desenvolvimento do pensamento em geral e, em particular no processo de ensino/aprendizagem. É por isso que se assinala que sem sensações, percepções e representações, não há desenvolvimento do pensamento; daí, ser importante, sempre que possível, além das palavras, usar representações visuais (VIANA, 2002, p.77).

Percebemos ao longo da passagem do filme, como os alunos ficavam chocados com os dados apresentados, principalmente por serem questões voltadas a sua realidade alimentar, houve um baque entre eles e ouvimos muitos dizendo que nunca mais comeriam certos alimentos. Ao encaminharmos a tarefa para a aula seguinte, que foi o pedido da coleta de embalagens, ficamos muito preocupadas, pois achávamos que muitos alunos iriam acabar comprando alguns alimentos e consumindo os apenas para ter as embalagens, no entanto ao final da aula muitos se encaminharam para as latas de lixo da escola, onde de imediato já recolheram muitas embalagens e isso de fato nos aliviou.

Durante a pesagem do açúcar e da gordura, que continham nas informações das embalagens, muitos alunos se mostraram sensibilizados e preocupados com a sua alimentação, pois agora eles podiam pegar e de fato ver, quanto açúcar consumiam e um simples refrigerante, sem nem ao menos perceber. Após a confecção dos cartazes, eles estavam decididos a anunciar isso para os demais amigos da escola, muitos ficavam ao lado de seus cartazes no recreio e explicavam para os colegas de outras turmas o que significava os saquinhos de açúcar no cartaz. 


\section{Vol. 2, n. 3 - Edição Especial: Ciclos Formativos em Ensino de Ciências.}

No entanto, passados alguns meses, percebemos que essa preocupação foi apenas momentânea, muitos alunos já voltaram a sua rotina normal de consumo de alimentos industrializados. Mas acreditamos que atingimos o objetivo da nossa aula, pois ao trabalharmos com os alunos sobre o assunto, demos a eles o poder de escolha. É muito difícil sensibilizar um aluno, por isso é importante que as atividades sobre a educação alimentar se repitam ao longo dos anos letivos, e que isto seja feito através de metodologias diferenciadas para que não se torne um assunto desgastante e desestimulante aos alunos.

Ao desenvolvermos o jogo como uma atividade que visava à associação através da degustação de alimentos, foi possível ver como metodologias diferenciadas podem trazer resultados positivos, envolvendo na aprendizagem mais sentidos além do ouvir e do enxergar, experienciar a ciência através dos sentidos é um fator facilitador do envolvimento do aluno e, portanto da aprendizagem (TUAN, 1980). Iniciando o quis, logo percebemos mais uma vez o motivo pelo qual desenvolvemos a atividade, todas as equipes em suma, acertavam as questões voltadas para a função da vitamina, mas chegando às questões que eram sobre o local onde se encontrava tal vitamina muitos acabavam errando.

Ao anunciarmos após a primeira questão, referente à fonte da vitamina, que as equipes que aviam errados deveriam degustar o alimento, todos os alunos iniciaram um alvoroço, ficaram espantados e ao mesmo tempo alegres, assim, muitos toparam de imediato degustar o alimento, outros, no entanto, optaram por não o fazer, apesar de termos incentivado, não obrigamos ninguém a consumir nenhum alimento, visto que muitos alunos poderiam se sentir mal em relação a isso. Algumas equipes, no entanto, que haviam acertado também queriam degustar o alimento e visto a insistência de muitos acabamos permitindo, afinal em relação à aprendizagem isso não implicaria em nada, portanto reformulamos esta regra juntamente com os alunos.

Podemos verificar que a nossa atividade, de fato foi proveitosa e cumpriu o seu objetivo após o desenvolvimento da avaliação referente a este conteúdo, onde os alunos não só demonstraram compreender a função das vitaminas assim como sabiam apontar onde as mesmas poderiam ser encontradas. Muitos dos alimentos citados como fonte 


\section{Vol. 2, n. 3 - Edição Especial: Ciclos Formativos em Ensino de Ciências.}

para estas vitaminas eram aquele que havíamos levado para a sala de aula e utilizado no quis.

Foi possível compreender, que de fato, o lúdico é muito importante para o desenvolvimento mental dos alunos, auxilia na comunicação entre professor e aluno e possibilita a aprendizagem, "é importante que o professor busque sempre ampliar seus conhecimentos sobre o lúdico e que utilize com mais frequência técnicas que envolvam jogos, proporcionando o desenvolvimento integral de seus alunos" (ALVES; BIANCHIN, 2010, p.286). Segundo Oliveira (1985, p. 74) a ludicidade consiste em:

[...] um recurso metodológico capaz de propiciar uma aprendizagem espontânea e natural. Estimula a crítica, a criatividade, a sociabilização. Sendo, portanto reconhecido como uma das atividades mais significativas senão a mais significativa - pelo seu conteúdo pedagógico social.

Mas não basta apenas alterar a metodologia de ensino do professor, este precisa também se enxergar e se portal como mediador durante qualquer metodologia, de uma forma que a atividade de fato vise à agregação de conhecimentos, nenhuma metodologia será boa se não for bem mediada. No caso dos jogos didáticos, a atenção deve estar dividida ente um bom planejamento para a atividade, visando possíveis perguntas a serem feitas para os alunos, assim como devemos dar atenção para a leitura de referências que possam ajudar o professor em seu trabalho docente. Podemos citar: "Jogo, brinquedo, brincadeira e a educação" de Kishimoto (2011), e "A formação social da mente" de Vygotsky (2007), que podem vir a servir de base para os professores no desenvolvimento de jogos em suas aulas.

Os jogos didáticos podem ser considerados boas ferramentas para a aprendizagem uma vez que permitem o trabalho em equipe e a sistematização de argumentos entre os colegas durante a formulação das respostas. Outro ponto positivo é que através das perguntas o professor pode iniciar o desenvolvimento do processo de investigação, onde ao instigar os alunos a formularem e exporem seus argumentos, ele pode perceber o desenvolvimento da turma em relação aos conceitos e assim revisar e retomar aquilo que se mostra pertinente.

O jogo pode se tornar muito interessante, durante a metodologia de aprendizagem, uma vez que pode estar constituído de figuras e outros elementos, como a degustação de 


\section{Vol. 2, n. 3 - Edição Especial: Ciclos Formativos em Ensino de Ciências.}

alimentos, que estimulam ainda mais o interesse do aluno para a participação e através desta sensibilização o aluno de fato aprende. Segundo Alves e Bianchin (2010, p. 248): "o jogo ajuda-o a construir suas novas descobertas, desenvolve e enriquece sua personalidade e simboliza um instrumento pedagógico que leva o professor à condição de condutor, estimulador e avaliador da aprendizagem”. O jogo além de estimular a aprendizagem de conceitos, é uma oportunidade de desenvolvimento para as crianças, desenvolvendo habilidades sociais, pois não basta entender as regras, precisa-se respeitá-las e uma vez que se joga com mais pessoas, precisa-se respeitas o outro.

Todavia, vale ressaltar que o jogo é uma oportunidade de desenvolvimento. Jogando a criança experimenta, inventa, descobre, aprende e confere habilidades. Sua inteligência e sua sensibilidade estão sendo desenvolvidas. A qualidade de oportunidades que são oferecidas à criança por meio de jogos garante que suas potencialidades e sua afetividade se harmonizem. Dessa maneira, pode-se dizer que o jogo é importante, não somente para incentivar a imaginação nas crianças, mas também para auxiliar no desenvolvimento de habilidades sociais e cognitivas (ALVES; BIANCHIN, 2010, p.286).

Para Vygotsky (2007) é durante o jogo que podemos perceber o estado cognitivo da criança e revela a forma como ela aprende. A brincadeira abre um grande espaço para o desenvolvimento de conceitos e é apenas através destes que se dará a aprendizagem. O jogo consegue entender as necessidades da criança se tornando um meio adequado para a aprendizagem, "neste sentido, qualquer jogo empregado na escola, desde que respeite a natureza do ato lúdico, apresenta caráter educativo e pode receber também a denominação geral de jogo educativo" (KISHIMOTO, 2011, p. 22).

Desta forma o lúdico pode se tornar um suporte para o professor, pois torna mais dialética a relação entre teoria e prática, e facilita ao professor a reflexão da própria prática, muito importante para o professor, por conter o lúdico o jogo vem se tornando um método muito importante para a aprendizagem (SANTOS, 2007).

\section{CONCLUSÃO}

Concluímos, portanto, que o uso de filmes como ferramenta didática facilita a sensibilização dos alunos, uma vez que apresenta imagens e músicas e o audiovisual é algo que chama muito a atenção dos pequenos, podendo assim, ser usado com facilidade 


\section{Vol. 2, n. 3 - Edição Especial: Ciclos Formativos em Ensino de Ciências.}

para iniciar a educação alimentar. No entanto, percebemos ao longo do acompanhamento das aulas, que a sensibilização de fato ocorreu, mas foi momentânea, portanto, verificamos que este é um processo longo e que precisa de vários momentos de reflexão. Por isso é importante trabalhar a educação alimentar com os para que eles possam escolher o que querem em relação a sua alimentação sabendo como isso implicará em sua saúde.

O jogo também se mostrou efetivo para a aprendizagem e para resolver o problema que a turma apresentava para relacionar a vitamina e as suas fontes. Principalmente por proporcionar a aprendizagem pela experiência através dos sentidos, o jogo permitiu o uso dos cinco sentidos pelos alunos e assim atingiu a diversidade da sala de aula, pois muitos alunos aprendem de formas diferentes. O jogo também permite perceber o nível cognitivo dos alunos e a partir disso o professor pode dar continuidade a sua aula, voltando a conceitos que precisem ser analisados.

Ao refletir sobre todas essas aulas, fica muito nítida a importância que o PETCiências e os ciclos formativos do Grupo de Estudos e Pesquisa em Ciências e Matemática (GEPECIEM) teve em relação à reflexão sobre as minhas práticas engrandecendo minha formação. Bem como, o contato e diálogo com os demais participantes sobre diversas metodologias para o ensino, nos enriquecendo assim através da socialização das vivências. A formação inicial e continuada é muito importante no ensino, uma vez que a escola se apresenta cada vez mais diversa, onde não só o professor precisa estar constantemente se aprimorando em relação aos conceitos, mas também a forma como os alunos aprendem se altera, e assim surge a necessidade do professor reinventar a sua prática.

\section{REFERÊNCIAS}

ALVES, Luciana; BIANCHIN, Maysa Alahmar, O jogo como recurso de aprendizagem. Revista Psicopedagogia, v. 27, n. 83, p. 282- 287, 2010.

KISHIMOTO, Tizuco Morchida. Jogo, brinquedo, brincadeira e a educação. 14. ed. São Paulo: Cortez, 2011. 
Revista Insignare Scientia

Vol. 2, n. 3 - Edição Especial: Ciclos Formativos em Ensino de Ciências.

OLIVEIRA, Vitor Marinho de. O que é educação física. São Paulo: Brasiliense, 1985.

SANTOS, Santa Marli Pires dos. O lúdico na formação de professores. 7. Ed.

Petrópolis, RJ: Vozes, 2007.

TUAN, Yi-Fu. Topofilia: um estudo da percepção, atitudes e valores do meio ambiente. São Paulo: Difel, 1980.

VIANA, M. C. V. Perfeccionamiento del currículo para la formación de profesores de matemática en la UFOP. Tese de Doutorado. ICCP:Cuba, 2002.

VYGOTSKY, Lev Semenovich. A formação social da mente. São Paulo: Martins Fontes, 2007. 